\title{
Feasibility of Low Intensity Pulsed Ultrasound to Improve Cartilaginous Thickness in Osteoarthritic Knee
}

\author{
FATMA A. HANAFY, M.Sc. ${ }^{\mathbf{1}}$; SALWA F. ABDEL-MAJID, Ph.D. ${ }^{\mathbf{2}}$; MOHAMED F. ABDEL-LATIF, Ph.D. ${ }^{\mathbf{3}}$ and \\ HATEM MOHAMED AL-AZIZI, M.D. ${ }^{4}$ \\ The Department of Physical Therapy for Orthopedics, Faculty of Physical Therapy, Cairo ${ }^{\mathbf{1 , 2}}$ and MUST Universities and \\ The Department of Radiology, Faculty of Medicine, Cairo University ${ }^{4}$, Giza, Egypt
}

\begin{abstract}
Background: It is clear that $\mathrm{OA}$ is a complex multifactorial disease process involving cartilage catabolism and anabolism. LIPUS may play a potential chondroprotective role in chondrocyte metabolism; enhance cell proliferation and matrix production.

Aim of Study: Is to investigate the effect of Low Intensity Pulsed Ultrasound (LIPUS) therapy on cartilage repaire in patient with grade 2 or 3 osteoarthritis of the knee.

Methods: Subjects were assigned in one pre and post study groupand receive 20 minutes of LIPUS with power 60 $\mathrm{mw} / \mathrm{cm}$ and frequency $100 \mathrm{~Hz}$ over the medial tibiofemoral compartment of the knee of both lower limbs and that was 3 times per week for successive three months. The clinical measures were obtained before the first session and after 36 th session, using the Musculoskeletal Ultrasound (MSUS) to assess cartilage thickness.
\end{abstract}

Results: There was a significant difference between MSUS before and after LIPUS treatment in left knee with $p$-value $=$ 0.01 . The mean MSUS increased from 1.81 to 2.27 with a difference 0.45 and in right knee with $p$-value $=0.001$. The mean MSUS increased from 2.09 to 2.44 with a difference 0.34 .

Conclusion: LIPUS has a statistical difference over increasing cartilage thickness measured by M.S.U.S in patient with mild to moderate knee osteoarthritis.

Key Words: Knee osteoarthritis - Ultrasound therapy - LIPUS - Musculoskeletal US.

\section{Introduction}

OSTEOARTHRITIS is a degenerative osteoarthropathy, and affects typically knee, hip, spine and hand joints. It differs from simple wear and tear $[1,2]$ caused by abnormal joint loading and

Correspondence to: Dr. Fatma A. Hanafy, The Department of Physical Therapy for Orthopedics, Faculty of Physical Therapy, Cairo University frictional wear [3]. OA may have influence on the quality of life due to functional deficit, pain and stiffness of the osteoarthritic patient [4]. A loss of equilibrium between synthesis and degradation of cartilage components produces alterations of its structure and progressive cartilage thinning [5]. So it has been recently accepted as a joint cartilage disease [6]

Knee osteoarthritis is the most common presentation of OA, with an estimated prevalence between $12 \%$ and $35 \%$ in the general population [7]. Generally can be subcategorized into primary (idiopathic) and secondary OA [8]. OA has traditionally been diagnosed with radiographs that demonstrate Joint Space Width (JSW) and osteophytes. Recently, modalities such as Magnetic Resonance Imaging (MRI) and Ultrasound (US) have enhanced OA diagnosis [9]. But, Ultrasonography (US) has long been the domain of radiologists. However, with advances in technology and wide availability. US is being used as an extension to physical examination. It has become the primary modality of imaging for most of MSK conditions

Low Intensity Pulsed Ultrasound (LIPUS) is a representative therapy in the orthopedic field and [11].It is a form of mechanical energy transmitted transcutaneously by high frequency acoustic pressure waves. with intensity of $\left(30 \mathrm{~mW} / \mathrm{cm}^{2}\right)$ which is the range of ultrasound intensities used for diagnostic purposes $\left(1-50 \mathrm{~mW} / \mathrm{cm}^{2}\right)$ and is regarded as non-thermal and non-destructive. The LIPUS device produces a $200 \mathrm{gs}$ burst of $1.5 \mathrm{MHz}$ acoustic sine waves, that repeats at a modulation frequency of $1 \mathrm{mHz}$, and provides a peak pressure of 30 $\mathrm{mW} / \mathrm{cm}^{2}[12]$ 
Low Intensity Pulsed Ultrasound (LIPUS) has been used successfully for bone fracture repair and has therefore been suggested for cartilage regeneration. However, previous in vitro studies with chondrocytes show conflicting results as to the effect of LIPUS on the elaboration of extracellular matrix [13]. Also it promotes type-IX collagen accumulation, thus resulting in an increased matrix production and proliferation of chondrocytes [14]

\section{Material and Methods}

This study was conducted in the out-patient clinic of Faculty of Physical Therapy, Misr University for Science and Technology. Subjects were selected by applying convenient sample selection method and received the intervention protocol for three successive months at the period from (October 2018 to January 2019). Thirty two female with mild and moderate osteoarthritic knees according to the classification by kellgren and Lawrence [15] aging 50-70 years OA according to the criteria of the American College of Rheumatology [16] and with BMI between (28.7-47.2). Patients with history of serious lower limb or spine injury throughout the time of the study, history of previous surgeries or trauma in lower limb or spine, concurrent injuries in lower limb or spine and patient taking any medications that may affect on knee osteoarthritis throughout the time of the study were excluded from this study.

All participants gave written informed consent prior to participation in the study approved by Research Ethical Committee, Faculty of Physical Therapy, Cairo University (No:P.T.REC/012/ 002043).

\section{Instruments:}

Scale of weight and height, musculoskeletal ultrasongraphy and OSTEOTRON IV-ultrasound bone growth stimulator. (3-3-3 Toyotama-Minami, Nerima-ku, Tokyo 176-0014, Japan-TEL: 81-33994-4619-FAX: 81-3-3994-1465 URL: http:// . www.itocoltd.com e-mail: itocoltd@itolator.co.jp).

\section{Intervention protocol:}

Subjects were assigned in one pre and post study group with BMI between (28.7-47.2) determined according to the following formula: $\mathrm{BMI}=$ $\mathrm{kg} / \mathrm{m}^{2}$ where $\mathrm{kg}$ is a person's weight in kilograms and $\mathrm{m}^{2}$ is their height in meters squared. A BMI of 25.0 or more is overweight, while the healthy range is 18.5 to 24.9 .

\section{Low intensity pulsed ultrasound application:}

The patient was supine with 30 degree flexion knee which might have influenced the correct penetration of the energy in the area of intended treatment and receive 20 minutes of LIPUS with power $60 \mathrm{mw} / \mathrm{cm}$ and frequency $100 \mathrm{~Hz}$ over the medial tibiofemoral compartment of the knee of both lower limbs (dominant and non dominant) and that was 3 times per week for successive three months. They were evaluated before and after treatment using the musculoskeletal ultrasound and all examination results were recorded from before and after LIPUS treatment for the same subject. In this study comparisons were made within the same subject at the same affected knee, so all risk factors affecting severity of knee OA were equal throughout the time of the study within the same subject. All measurements were recorded by the same examiner to avoid inter-tester variability.

\section{Results}

All statistical measures were performed using the Statistical Package for Social Science (SPSS) program Version 16 for windows. Prior to final analysis, data were screened for normality assumption, and presence of extreme scores. This exploration was done as a pre-requisite for parametric calculation of the analysis of difference. To determine similarity between the groups at base line, participant's age, weight, height, and Body Mass Index (BMI) were compared using independent $t$ tests.

Table (1) represents that was a significant difference between MSUS before and after LIPUS treatment in right knee with $p$-value $=0.001$ and paired $t$-test $=4.01$. As illustrated in Fig. (1) the mean MSUS increased from $2.09 \pm 0.55$ before LIPUS treatment to $2.44 \pm 0.51$ after LIPUS treatment with a difference or an increase equal to 0.34 which means that the treatment was effective in increasing MSUS for right knee.

Table (1): Difference between Musculoskeletal Ultrasonography (MUSU) before and after LIPUS treatment in right knee.

\begin{tabular}{lcc}
\hline MSUS & Mean & SD \\
\hline Before LIPUS treatment & 2.09 & 0.55 \\
After LIPUS treatment & 2.44 & 0.51 \\
Difference & \multicolumn{2}{c}{0.34} \\
$t$-value & \multicolumn{2}{c}{4.01} \\
$p$-value & \multicolumn{2}{c}{$0.001 *$} \\
\hline
\end{tabular}

*: Significant at $p$-value $<0.05$. 


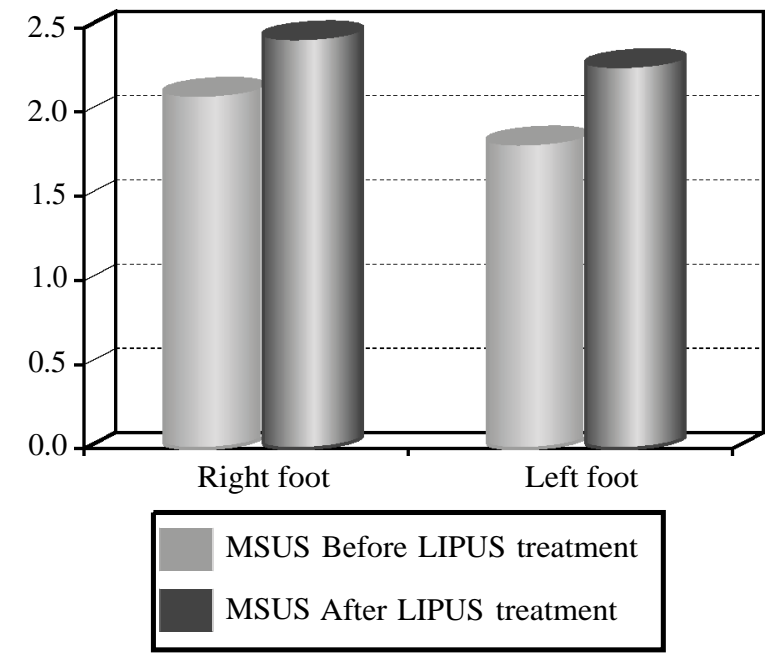

Fig. (1): Difference between MSUS before and after LIPUS treatment in both knee.

Table (2) represent that was a significant difference between MSUS before and after LIPUS treatment in left knee with $p$-value $=0.01$ and paired $t$-test $=2.96$. As illustrated in Fig. (1) the mean MSUS increased from $1.81 \pm 0.33$ before LIPUS treatment to $2.27 \pm 0.55$ after LIPUS treatment with a difference or an increase equal to 0.45 which means that the treatment was effective in increasing MSUS for left knee and the effect was better than the right knee where the increase was only 0.34 ).

Table (2): Difference between MSUS before and after LIPUS treatment in left knee.

\begin{tabular}{lcc}
\hline MSUS & Mean & SD \\
\hline Before LIPUS treatment & 1.81 & 0.33 \\
After LIPUS treatment & 2.27 & 0.55 \\
Difference & \multicolumn{2}{c}{0.45} \\
$t$-value & \multicolumn{2}{c}{2.96} \\
$p$-value & \multicolumn{2}{c}{$0.01^{*}$} \\
\hline
\end{tabular}

*: Significant at $p$-value $<0.05$.

\section{Discussion}

There are different types of cartilage, show different reactions to LIPUS stimulation as endochondral cartilage, and hyaline cartilage [17]. Which known as articular cartilage that covers the condyles of bones, and provide pain-free flexible movement. Also it is composed of a few chondrocytes and an extracellular matrix [18,19]. However cartilage does not have blood vessels or nerves; therefore, it has a limited capacity for intrinsic healing and repair. Sowhen it is damaged eventually progresses to osteoarthritis [20,21].

So the aim of the current study was to investigate the effect of low intensity pulsed ultrasound stimulation on knee osteoarthritis and the integrity of articular cartilage of the knee and its thickness.
The finding of current study revealed that there is asignificant difference in cartilage thickness in domin ant and non dominant leg.

Till the author knowledge the effect of (LIPUS) on the tested variables of interestamong the osteoarthritic women. Some studies have reported that, the LIPUS may influence both chondrocyte proliferation and matrix production of articular human cartilage in vitro, so it might provide a feasible tool for cartilage tissue repair in osteoarthritic patients [17].

The findings of the current study revealed that treatment program by (LIPUS) stimulation of knee $\mathrm{OA}$ in female can help to increase integrity of articular cartilage and This finding was matched with the results of recent clinical trials of Gessal et al., (2015) who studied effect of mechanical stimulus produced by low-intensity ultrasonic energy (spatial average temporal average intensities between $03-62 \mathrm{~W} / \mathrm{cm} 2$ ) promotes chondrogenesis in human cell cultures and animal models of cartilage injury [4]

According to review article in the role ofLIPUS on osteoarthritis reported that PLIUS alleviated surface irregularities, decreased matrix loss degree with the inhibition of TGF-beta1 production, and attenuated the proceeding of cartilage degeneration in Hartley guinea pigs, which might be an alternative therapy method for human osteoarthritis. LIPUS down-regulated the Mankin scores and the expression level of MMP- 13 in rabbit articular cartilage of animal model of Osteoarthritis [23]

Another study demonstrates that LIPUSstimulation, at the cell resonance-frequency of 5.0$\mathrm{MHz}$ increased the ciliary length in chondrocytes (up to 1.7-fold) when compared to the control groups. Increases in the cilia length were dependent on the duration and pressure-amplitude of the LIUS-signal. US-stimulation also impacted the orientation of the primary cilium in chondrocytes [23] .

\section{Conclusion:}

The conducted LIPUS treatment program was capable of providing a feasible tool for increasing cartilage integrity in mild and moderate degree arthritis in knee osteoarthritis throughout stimulating chondrocyte proliferation and matrix production.

\section{Acknowledgements:}

The authors would like to thank all the patients who kindly participated in the study. 


\section{References}

1- SAARAKKALAYZ S., WARIS P., WARIS V., TARKIAINEN I., KARVANEN E., AARNIO K.J. and KOSKI J.M.: Diagnostic performance of knee ultrasonography for detecting degenerative changes of articular cartilage: Osteoarthritis and Cartilage, 20: 376e38, 2012.

2- JI1 J.B., LI2 X.F., LEI LIU, WANG G.Z. and YAN1 X.F.: Effect of low intensity pulsed ultrasound on expression of TIMP-2 in serum and expression of mmp-13 in articular cartilage of rabbits with knee osteoarthritis: Asian Pacific Journal of Tropical Medicine, 8 (12): 1043-8, 2015.

3- BARDOLOI B., BHUTIA C., BHATIA D.* and PAUL S.: Knee Osteoarthritis: An Overview of Recent Interventions Avestia Publishing Journal of Biomedical Engineering and Biosciences Volume 4, Year, Journal ISSN, 2017.

4- GESSAL J., YUSUF I., PATELLONGI I. and LAWRENCE G.: Effect of Low-Intensity Pulsed Ultrasound on Quality of Life of Knee Osteoarthritis: American Journal of Health Research, 3 (3): 166-9, 2015.

5- FINUCCI1 A., IORGOVEANU V., RUTIGLIANO I.M., SCIROCCO C. and IAGNOCCO A.: Utilizing ultrasound in the diagnosis and management of osteoarthritis: Int. J. Clin. Rheumatol., 10 (6): 433-40, 2015.

6- YiLMAZ V., KARADAŞ O., DANDINOGLU T., UMAY E., CAKC1 A. and TAN A.K.: Efficacy of extracorporeal shockwave therapy and low intensity pulsed ultrasound in a rat knee osteoarthritis model: A randomized controlled trial: Eur. J. Rheumatol., 4: 104-8, 2017.

7- SÁNCHEZ L.A., RICHARDSON J.A. and MacINTYRE N.J.: Efficacy of ultrasound therapy for the management of knee osteoarthritis: A systematic review with metaanalysis: Osteoarthritis and Cartilage, 18: 1117e1126, 2010.

8- MARK D., ADAM A. and NAVIN D.: Kellgren-Lawrence Classification of Osteoarthritis: Clin. Orthop. Relat. Res., 474: 1886-93, 2016.

9- BRAUN H.J. and GOLD G.E.: Diagnosis of osteoarthritis: Imaging: Braun H.J., Gold G.E., Diagnosis of osteoarthritis: Imaging, Bone, doi: 10.1016/j.bone.2011.11.019, 2011.

10- PATIL P. and DASGUPTA B.: Role of diagnostic ultrasound in the assessment of musculoskeletal diseases: Ther. Adv. Musculoskel. Dis., 4 (5): 341-55, 2012.

11- YUAN L.J., NIU C.C., LIN S.S., YANG C.Y., CHAN Y.S., CHEN W.J., STEVE W.N. and UENG S.W.: Effects of low-intensity pulsed ultrasound and hyperbaric oxygen on human osteoarthritic chondrocytes: Journal of Orthopaedic Surgery and Research, 9: 5, 2014.

12- De GUSMAO C.V.B., PAULI J.R., SAAD M.J.A., ALVES J.M., and BELANGERO W.D.: Low-intensity Ultrasound Increases FAK, ERK-1/2, and IRS-1Expression of Intact Rat Bones in a Noncumulative Manner. Clin. Orthop. Relat. Res., 468: 1149-56, 2010.
13- VAUGHAN N.M., GRAINGER J., BADER D.L. and KNIGHT M.M.: The potential of pulsed low intensity ultrasound to stimulate chondrocytes matrix synthesis in agarose and monolayer cultures. Med. Biol. Eng. Comput., 48: 1215-22, 2010.

14- TAKEUCHI R., RYO A., KOMITSU N., TAKAGAKI Y.M., FUKUI A., TAKAGI Y., SHIRAISHIT, MORISHITAS, YAMAZAKI Y., KUMAGAI K., AOKI I. and SAITO T.: Low Intensity Pulsed Ultrasound Activate The Phosphatidylinositol 3 Kinase/Akt Pathway And Stimulates The Growth Of Chondrocytes In Three-dimensional Cultures: A Basicsciencestudy:Arthritis Research \& Therapy, 10: R77 (Doi:10.1186/Ar2451, 2008.

15- KELLGREN J.H. and LAWRENCE J.S.: Radiological assessment of osteoarthrosis: Ann. Rheum. Dis., (19571, $16,494)$.

16- ALTMAN R., ASCH E. and BLOCH D.: Development of criteria for the classification of osteoarthritis of the knee. Arthritis Rheum., 29: 1039-49, 1986.

17- KORSTJENS C.M.K., RIJT R.H.H., ALBERS H.R. SEMEINS C.M. and NULEND J.K.: Low-intensity pulsed ultrasound affects human articular chondrocytes in vitro: Med. Biol. Eng. Comput., 46: 1263-70, 2008.

18- CHENG K., XIA P., LIN Q., SHENS, GAO M., REN S. and Xueping L.: Effects of low-intenisty pulsed ultrasound on integrin-FAK-PI3K/AKT mechanochemical transduction in rabbit osteoarthritis chondrocytes: Ultrasound in Medicine \& Biology 1-10, 2014.

19- XIA P., SHEN S., LIN Q., CHENG K., M.S., REN S., GAO M. and LI X.: Low-Intensity Pulsed Ultrasound Treatment at an Early Osteoarthritis Stage Protects Rabbit Cartilage From Damage via the Integrin/Focal Adhesion Kinase/Mitogen-Activated Protein Kinase Signaling Pathway: The American Institute of Ultrasound in Medicine |J. Ultrasound Med., 34: e61-e69 | 0278-4297, 2015.

20- UDDIN S.M.Z., RICHBOURGH B., DING Y., HETTINGHOUSE A., D.E., KOMATSU A.D.E., QIN Y.X. and LIU J.: Chondro-protective effects of low intensity pulsed ultrasound: Osteoarthritis and Cartilage, 24: 1989e1998, 2016.

21- NISHIDA Y.T., KUBOTA Y.Z.S., AOYAMA Z.E., YAMANAKA X.N., K.M. LYONS K.K.M. and TAKIGAWA M.: Low-Intensity Pulsed Ultrasound (LIPUS) treatment of cultured chondrocytes stimulates production of $\mathrm{CCN}$ family protein 2 (CCN2), a protein involved in the regeneration of articular cartilage: Mechanism underlying this stimulation: Osteoarthritis and Cartilage xxx, 1-11, 2016.

22- TIAN S., LI M., DONG F. and ZHANG F.: Review Article The role of low-intensity pulsed ultrasound on bone and soft tissue healing: Int. J. Clin. Exp. Med., 9 (7): 124506, 2016.

23- SUBRAMANIAN A., BUDHIRAJA G. and SAHU N.: Chondrocyte primary cilium is mechanosensitive and responds to low intensity-ultrasound by altering its length and orientation: International Journal of Biochemistry and Cell Biology, 91: 60-4, 2017. 


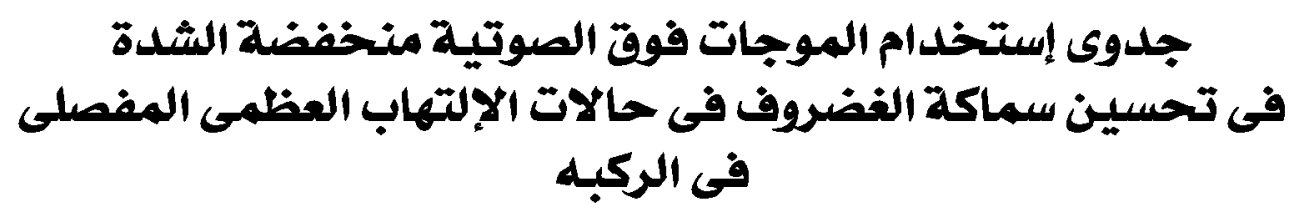

نظراً لما تصدثه خشونة الركبه من تغييرات سلبية على المفصل والتى قد تؤدى إلى تاكل الفضاريف فقد إستوجبت هذا من الباحثين فى

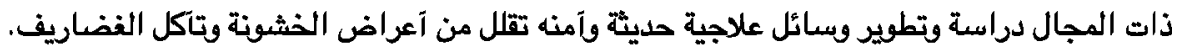

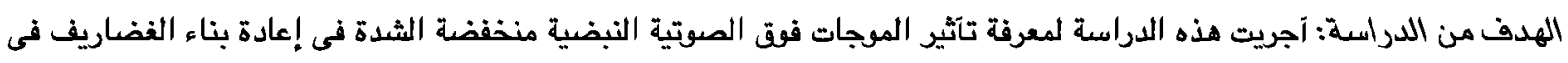

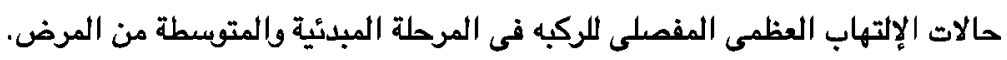

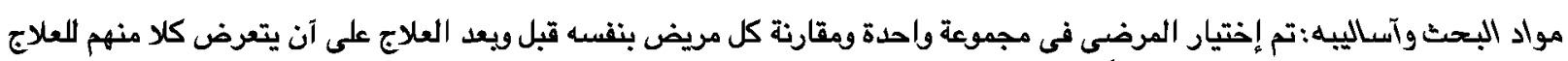

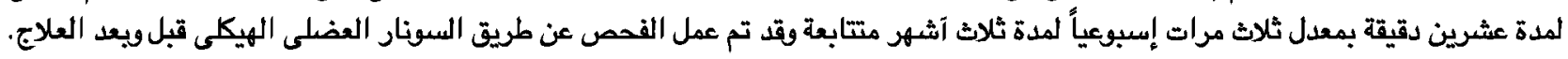
الإستتاج: آوضحت نتائج السونار آن الموجات فوق الصوتية النبضية منففضة الشدة قد يكون لها تآثير إيجابى إحصائى فى إعادة بناء 